\title{
Influence of the Openness of Inlet One-way Valve on the Flow Characteristics in Series- Parallel Centrifugal Pumps
}

\author{
Hao YAN, Qiang LI, Liang CHEN, Yu ZHANG, Jaini RAGHU
}

\begin{abstract}
Series-parallel centrifugal pumps realize series and parallel running conditions through unique inlet one-way valve and reversing valve structures. In the running process, changes in the openness of the inlet one-way valve cause changes in the running parameters of the two impellers and in the inner flow field, thereby inducing pressure fluctuation and intensifying unit vibration. In this study, the change law of internal flow of the series-parallel centrifugal pumps was disclosed under different openness degrees of the inlet one-way valve and its internal relationship with pressure fluctuation was clarified by combining numerical simulation and model experiment. The major causes of pressure fluctuation and hydraulic performance changes induced by changes of internal flow field were analyzed. Results show that when the openness of the one-way valve is smaller than $20^{\circ}$, the two impellers present different operational states under parallel connection, which deteriorate the hydraulic performance of pumps. Decreasing the openness of one-way valve can reduce the pressure around the inlet of the second-stage blade and induce eddies; however, it slightly influences the pressure at the inlet of the first-stage blade. With the changes in the openness of the inlet one-way valve, the fluctuation frequency at the occurrence of maximum fluctuation remains the same; however, the fluctuation amplitude changes considerably. The fluctuation amplitude under small openness is lower than that under large openness. Conclusions obtained in the study have important implications in reducing the vibration and noise of series-parallel centrifugal pumps.
\end{abstract}

Keywords: fluid flow; inlet one-way valve; pressure fluctuation; series-parallel centrifugal pump

\section{INTRODUCTION}

Series-parallel centrifugal pumps, with characteristics of small land occupation and wide applicable operating conditions, have been used extensively in many fields, such as ships and fire engineering. These pumps realize series and parallel running conditions through conversion between inlet one-way valve and outlet reversing valve. During series running conditions, the inlet one-way valve is closed, and fluid forms the small-flow and high-head conditions through pressurization of the two-level impellers. These conditions are for fire protection and pressurization. For parallel running conditions, the oneway valve is opened; the reversing valve is changed to the inlet direction of the second-stage impeller, and fluid passes through the first- and second-stage impellers simultaneously; these conditions realize large-flow and low-head conditions and are mainly used for rapid drainage, dewatering, cooling, bilge conveying, and cleaning. On the basis of the structural design of seriesparallel centrifugal pumps, two impellers and pumping chambers generally use the same hydraulic model, which is beneficial for the equilibrium of axial forces and the reduction of the time of making molds [1,2]. In view of hydraulic design, the inlet conditions of two impellers are changed, and the hydraulic performance deviates due to different inlet and outlet conditions of the two impellers, particularly because of the existence of an inlet one-way valve. Fluid easily develops reflux and eddies when it converges at the outlet because of different outlet channel structures after the two impellers. Such reflux and eddies are disadvantageous to flow and may induce pressure fluctuation, thereby increasing vibration noise of the unit $[3,4]$. However, the change mechanism of pressure fluctuation under different openness degrees of inlet oneway valve still remains unknown.

With the rapid development of the ship industry, high requirements on unit vibration must be satisfied. The vibration reductions of series-parallel centrifugal pumps have attracted wide attention from researchers. For structures, series-parallel centrifugal pumps are a type of centrifugal pumps, and the vibration performance has similar variation laws. The dynamic and static coupling between impeller and volute can cause fluid-induced vibration because the centrifugal pumps have high-speed rotating impellers and static volutes. Moreover, fluid separation occurs in the pumps when they deviate from the designed working condition, thereby inducing eddies and vortex against fluid flow and finally intensifying unit vibration [5]. For research methodology, the combination of computational fluid dynamics (CFD) technology and model experiment is a mature method for studying fluid flow, fluid-induced vibration, and non-equilibrium radial forces in centrifugal pumps. Abundant researches have proved the accuracy of this method [6-9]. In view of flow dynamic principles in fluid mechanics, the vibration noise of series-parallel centrifugal pumps under parallel state is stronger than that under the series state. This difference in strength of vibration noise is caused by the large difference of internal flow characteristics under the two conditions. Particularly, under the series state, different openness degrees of inlet one-way valve cause different running conditions of the two impellers, thereby increasing pressure fluctuation in the pumps [10]. Therefore, this study aims to discover the flow change law in seriesparallel centrifugal pumps under different openness degrees of inlet one-way valve accurately and determine the relationship between different openness degrees of the inlet one-way valve of the physical model and pressure fluctuation.

\section{STATE OF THE ART}

Centrifugal pumps are extensively used universal machinery. Researchers have conducted abundant studies on the hydraulic performance and pressure fluctuation of these pumps [11]. Rosen [12] studied the relationship between external characteristic curve and vibration signal of centrifugal pumps by using a model experiment and mathematical statistics and found that the flow range corresponded to the sharp increase of vibration. However, 
the author did not explore the root cause of vibration and intensifying vibration. Liu et al. [13] analyzed the influence of prewhirl angle and axial distance on energy performance and pressure fluctuation for a centrifugal pump with inlet guide vanes by using CFD and found that prewhirl angle had an obvious impact on pump energy performance and the maximum amplitudes of pressure fluctuations on the blade leading edge of the pressure and suction sides decrease by $69 \%$ and $89 \%$, respectively. However, the authors did not analyze pressure fluctuation and fluidinduced vibration caused by such turbulence. Moreover, the formation mechanism of internal pressure fluctuation in centrifugal pumps with guide vanes could provide references for multilevel pumps vibration and noise reduction.

Studies showed that the rotor-stator interaction between the impeller and guide vane was the main cause of pressure fluctuation in pumps $[14,15]$. Pressure fluctuation under small flow conditions was relatively strong [16, 17]. Khalifa et al. [18] adopted a model experiment to study the double-volute centrifugal pump and analyze pump vibration information under different conditions. They pointed out that the strong interaction between the blades and volute of the centrifugal pump was the major cause of high-pressure fluctuation. However, rotor-stator interaction caused in such structure was still relatively different with that among impellers, guide vanes, and volutes. Ruanet al. [19] experimental studied a pneumatic control system based on metering-outcontrol to prevent high turbine speed and minimize the consumption of the pneumatic submersible pump in irrigation and drainage and automatically adjust the pressure of the submersible pump under no-load and load conditions. Liu et al. [20] used large eddy simulation (LES) turbulence model to study the internal flow field of the double-suction centrifugal pump with different blades installation modes and analyze the pressure fluctuation in the volute tip. The authors concluded that the staggered arrangement of blades could reduce pressure fluctuation. However, the inflow conditions of the double-suction pump and of the seriesparallel centrifugal pumps, which influenced the hydraulic performances, were different due to the existence of a oneway valve. Si et al. [21] predicted pressure fluctuation in centrifugal pumps using a shear stress transport-scaleadaptive simulation (SAS) turbulence model and verified the accuracy of this model by utilizing a model pump test. Predictions of centrifugal pumps noise have become the key research topic of the academic circle. Langthjem et al. [22] and Yang et al. [23] combined numerical simulation with model experiment to predict the noise of different centrifugal pump models. They concluded that pressure fluctuation caused by rotor-stator interaction between the blade and volute was the major cause of increased centrifugal pump noise. However, the relationships of inlet condition change with pressure fluctuation and noise still remained unknown. The series-parallel centrifugal pump had similar properties with ordinary centrifugal pumps. Nevertheless, changes in the hydraulic performance of series-parallel centrifugal pumps tended to intensify pressure fluctuation due to its unique structure. Chai et al. [10] adopted the fast Fourier transform and multiple coherence analysis to obtain vibration characteristics at the outlet of series-parallel centrifugal pumps and found that

the number of blades of the first-stage impeller mostly influenced the pressure fluctuation at the outlet of the pump. However, the research results were only limited under completely same inflow conditions at the inlet; thus, research results under changed conditions need to be further confirmed. Su et al. [24] used CFD technology to analyze the influence of inlet condition on the nonoverload performance of series-parallel centrifugal pumps and found violent pressure fluctuation at the inlet of the second-stage impeller under series conditions. However, the influences of the three inlet conditions on the one-way valve were ignored, and the relationship between nonoverload performance and pressure fluctuation was not analyzed.

As such, many studies have reported the hydraulic performance and pressure fluctuation of centrifugal pumps with different structural forms. However, series-parallel centrifugal pumps have a one-way valve structure at the inlet. Hence, the openness degree of the one-way valve changes in the running process, thereby influencing the hydraulic performance and pressure fluctuation of the pumps. Thus far, the relationships between one-way valve openness and hydraulic performance and pressure fluctuation of pumps remain unknown. In this study, physical models under different one-way valve openness degrees are constructed. The actual running conditions of the two impellers of the series-parallel centrifugal pump under different schemes are predicted by combining numerical simulation and model experiment. The fundamental causes of pressure fluctuation are also analyzed. Relevant research results in this work can provide some references for the vibration and noise reduction of pumps in the ship engineering industry.

The remainder of this paper is organized as follows. Section 3 describes the method used including calculation method of the numerical simulation and selection of cases optimization. Section 4 analyzes the laws of fluid flow and compares the pressure fluctuation and frequency spectrum characteristics in the series-parallel centrifugal pump under different cases. Finally, Section 5 presents the conclusions.

\section{METHODOLOGY}

\subsection{Model Construction and Analysis}

A series-parallel centrifugal pump is taken as the research object in this study. The series and parallel states are shown in Fig. 1. The first- and second-stage impeller hydraulic model uses the single-level centrifugal pump model with flow rate $Q=75 \mathrm{~m}^{3} / \mathrm{h}$ and head $H=80 \mathrm{~m}$. The running parameters under the series and parallel states are listed in Tab. 1. The specific geometric parameters of the hydraulic model are introduced in bibliography [3].

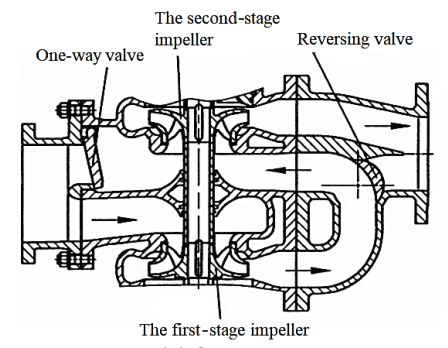

(a) Series state

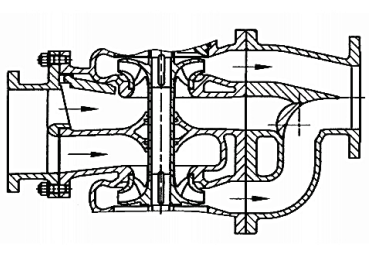

(b) Parallel state

Figure 1 Two working conditions of the series-parallel centrifugal pumps 
Table 1 Design parameters of the serial-parallel centrifugal pump

\begin{tabular}{|c|c|c|c|}
\hline $\begin{array}{c}\text { Working } \\
\text { conditions }\end{array}$ & $\begin{array}{c}\text { Flow rate } \\
Q\left(\mathrm{~m}^{3} / \mathrm{h}\right)\end{array}$ & $\begin{array}{c}\text { Head } \\
H(\mathrm{~m})\end{array}$ & $\begin{array}{c}\text { Rotation speed } \\
n(\mathrm{rpm})\end{array}$ \\
\hline Series state & 75 & 160 & 2900 \\
\hline Parallel state & 150 & 80 & 2900 \\
\hline
\end{tabular}

\subsection{Computation Method}

In the computational domain, the internal flow field is analyzed by solving three-dimensional steady and unsteady incompressible RANS equations with a renormalization group (RNG) $k-\varepsilon$ model by using a finitevolume solver. The ANSYS CFX software was used for CFD simulations. These were performed for the different cases, as steady-state single-phase simulations. This method can accurately predict the rotating and curvature flow in the flow passage components, which is verified by a large amount of previous work [25, 26]. The convective term is the second-order upwind scheme. The solution of the governing equation uses the pressure coupling algorithm with separation semi-implicit expression. The pump inlet uses the total pressure inlet, whereas the outlet uses the mass flow outlet. The wall function uses the noslip wall, and the reference pressure is $0 \mathrm{~Pa}$. The energy transmission between the rotating part (impeller) and the static part (guide vane) adopts the "frozen rotor" connection. The computation convergence standard is set to $10^{-5}$, and the medium uses water with $T=25^{\circ} \mathrm{C}$.

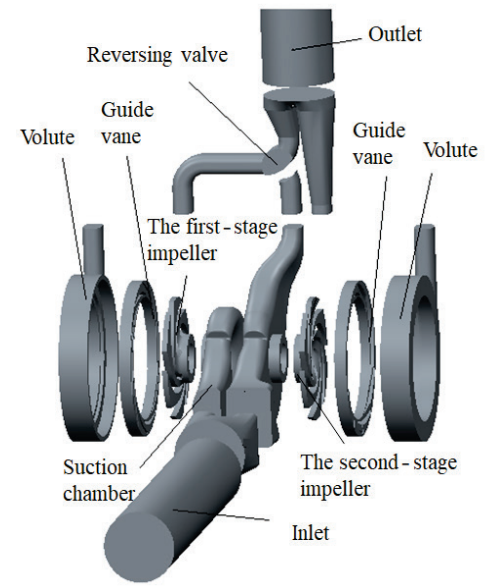

(a) Explosion view of the calculated area
Figure 2 Model water and meshing program

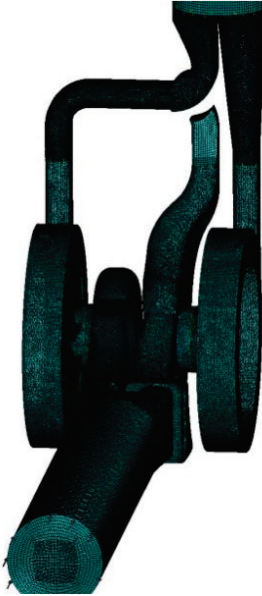

(b) Meshing program
The 3D physical model is constructed using the commercial software Pro/E. The inlet and outlet are expanded appropriately to reduce the influences of boundary conditions on the simulation results. The explosion view of the calculated area is shown in Fig. 2(a). The model is meshed by using ANSYS ICEM software. Given the complicated channel structure and multiple parts in the series-parallel centrifugal pump, all parts, except for the inlet and outlet pipes, use tetrahedral non-structured meshing, which has strong applicability. The grid numbers of water on the first- and second-stage impellers are 509,142 and 567,326, respectively; the grid numbers of water on the first- and second-stage guide vanes are 399,309 and 377,204, respectively; and the grid numbers of water on the first- and second-stage suction chambers are 1,094,480 and 1,482,534, respectively. The total grid number of the model water is $8,482,091$. On the basis of the grid independence analysis, the influence of the increase in grid numbers on head and efficiency is within $1.05 \%$. The full flow passage meshing in the series-parallel centrifugal pump is shown in Fig. 2(b).

In engineering, the second-stage inlet one-way valve is closed completely under the series state of the seriesparallel centrifugal pump. However, it should be completely open under the parallel state. Influenced by the fluid flow in the pump, the valve consistently fluctuates. To study the influence of valve fluctuation on the seriesparallel centrifugal pump, three instantaneous states of the valve fluctuation are selected, that is $20^{\circ}, 40^{\circ}$ and $65^{\circ}$ of valve openness degree $(\theta)$. The $65^{\circ}$ openness is basically close to the complete open state of the valve (Fig. 3).

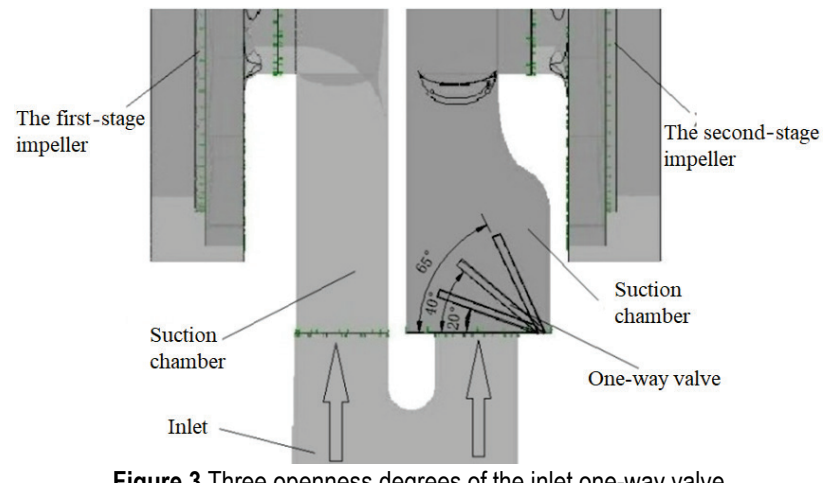

Figure 3 Three openness degrees of the inlet one-way valve

\subsection{Model Test}

An enclosed experimental setup is established to investigate the characteristics of the series-parallel centrifugal pump, as shown in Fig. 4. The experiments are conducted according to the requirements of the Chinese Grade 1 precision (GB3216-2005) and the international grade 1 precision (ISO9906-1999). The inlet and outlet pressures of SPCPs are accurately measured at approximately $\pm 0.1 \%$ using pressure sensors. The flow rate is accurately measured at approximately $\pm 0.1 \%$ using an electromagnetic flow meter. The electrical power input is measured with a three-phase torque meter. The overall measurement uncertainty is calculated from the square root of the sum of the squares of the systematic and random uncertainties [27]. The performance of the original pump at multi-flow rates is tested via the experiments.

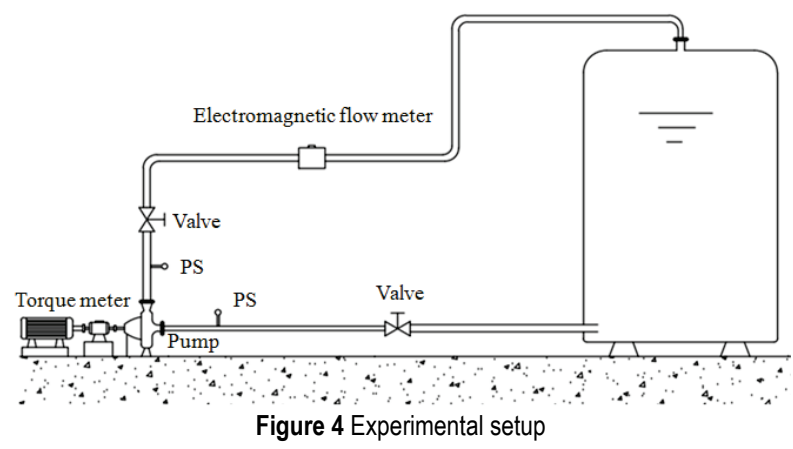

The total efficiency is obtained by computing $(\eta=$ $\left.Q\left(p_{\text {out }}-p_{\text {in }}\right) / P_{\text {shaft }}\right)$, where $p_{\text {out }}$ and $p_{\text {in }}$ are the testing pressures at the outlet and inlet of the pump, respectively, and $P_{\text {shaft }}$ is the input electrical shaft power measured using a three-phase torque meter. These parameters can be 
measured using testing sensors. Therefore, the total efficiency of the pump can be calculated directly from the above formula. The relationship among the parameters is shown by the curves in Fig. 4.

\section{RESULT ANALYSIS}

\subsection{Influence of the openness of Inlet One-Way Valve on the Hydraulic Performance of the Pump}

For the designed conditions of the series-parallel centrifugal pump, six working points in the flow range of $30-180 \mathrm{~m}^{3} / \mathrm{h}$ are selected for the parallel state. The firstand second-stage heads and the efficiency and axial power of the series-parallel centrifugal pump under complete open state of the second-stage valve are gained. The calculated results are compared with the experimental results (Fig. 5).

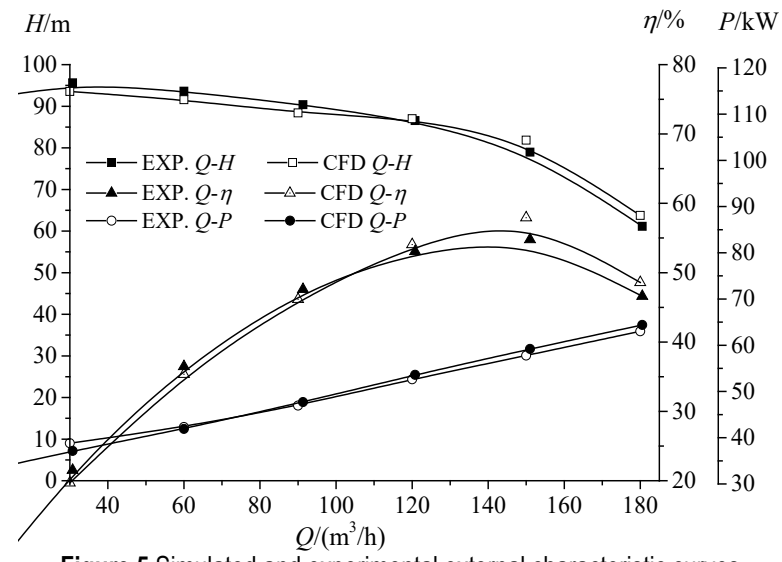

Figure 5 Simulated and experimental external characteristic curves

As shown in Fig. 5, the simulated external characteristic curves conform to the experimental one; however, a certain difference still exists. The CFD and experimental heads of the pump differ considerably under small and large flow rates. The maximum error under a small flow rate is $7.6 \%$ because the fluid flow in the pump is unstable, and pressure readings fluctuate greatly. Thus, the pressure readings of the inlet and outlet are neither the mean pressures nor the actual pressures at the inlet and outlet of the pump. Moreover, the arrangement mode of the pressure holes may influence the pressure readings to some extent. The simulation results are gained by integration of the channel sections. Under this circumstance, experimental results may be different with the simulation results. Under a large flow rate, cavitation exists in the experiment; however, cavitation is neglected in the steadystate simulation, thereby increasing the difference with the increasing of flow rate. Under a small flow rate, the experimental efficiency is slightly higher than the simulated efficiency due to the head error. Under a large flow rate, the experimental efficiency drops considerably due to the existence of cavitation. Under the designed condition, the errors of simulated efficiency and heads and the experimental results are kept lower than 5\%. Therefore, the model simulated the internal flow in the series-parallel centrifugal pump accurately under the designed condition and similar conditions. The simulation results are reliable.

\subsection{Influence of the Openness of Inlet One-Way Valve on Hydraulic Performance and Internal Flow}

Five working points close to the rated condition are selected for the steady calculation of parallel state under three openness degrees. The overall external characteristic curves of the pump are calculated (Fig. 6). The head and efficiency decrease with the openness of the inlet one-way valve. A smaller openness indicates a more considerable reduction of the head and efficiency. When the valve openness decreases from $65^{\circ}$ to $40^{\circ}$, the head and efficiency decline by less than $0.5 \%$. Hence, changes in the openness degrees in this range slightly influence the external characteristics of the pump. When the openness decreases to $20^{\circ}$, the head and efficiency decrease to some extent. Under the rated condition, the head and efficiency decrease by $2.66 \mathrm{~m}$ and $2.05 \%$, respectively. Furthermore, the declines of the head and efficiency increase gradually with the increase of flow rate.

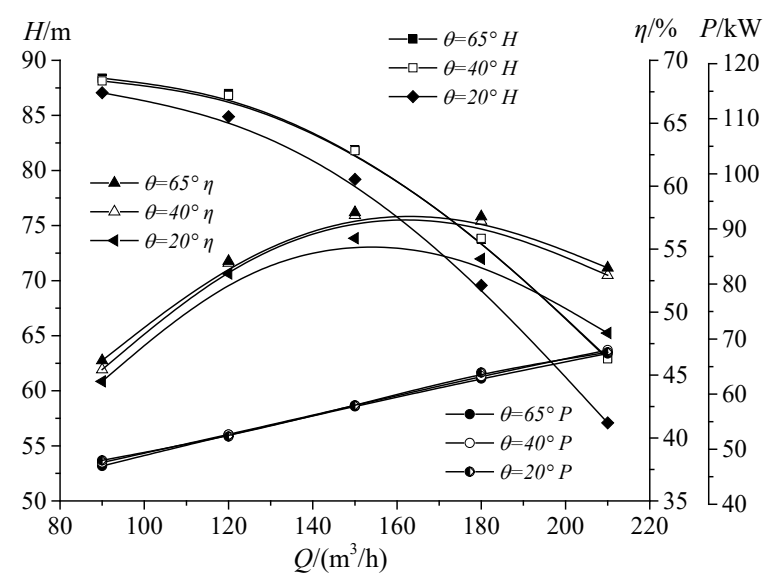

Figure 6 Parallel external characteristic curves of the series-parallel centrifugal pump under the three valve openness degrees

Changes in the overall pump head and efficiency cannot reflect the changes in each impeller. Therefore, statistical analysis on the changes in the external characteristics of the first- and second-stage impellers with the overall flow rate are performed (Fig. 7).

The variation trend of the external characteristic curve of the second-stage impeller with the openness of the inlet one-way valve is close to the overall trend of the pump. Efficiency and head declines are slightly higher than the overall declines of the pump. When $\theta=20^{\circ}$, the head and efficiency decrease by $3.2 \mathrm{~m}$ and $4 \%$ under the rated condition. The variation trend of the external characteristic curve of the first-stage impeller with this openness of the inlet one-way valve is completely different. When $\theta=40^{\circ}$, the head and efficiency change slightly. When the openness decreases to $20^{\circ}$, the head decreases slightly. The head is decreased by $1.3 \mathrm{~m}$ under the rated condition. However, the efficiency presents the opposite trend under this $\theta$. Efficiency under a small openness degree is slightly higher than that under a large openness degree. Moreover, efficiency under a smaller flow rate increases more than that under a larger flow rate.

Changes in the first- and second-stage flow ratios with the overall flow of the pump under the three openness degrees are shown in Fig. 8. $C_{q}$ denotes the first- and second-stage flow ratios; it is equal to the second-stage 
flow rate divided by the first-stage flow rate. The first-stage outlet pipes of the series-parallel centrifugal pump are more complicated than the second-stage outlet pipes. Therefore, the resistance of the first-stage pipe is larger than that of the second-stage pipe. Hence, the flow rate of the second stage is higher than that of the first stage under all working conditions of parallel state. The flow rate of the second stage can also reach 1.61 times that of the first stage to the maximum extent. With the reduction of valve openness, the resistance of the second-stage pipe increases, thereby reducing the flow rate of the second stage. The flow rates of the first and second stages tend to be equal.

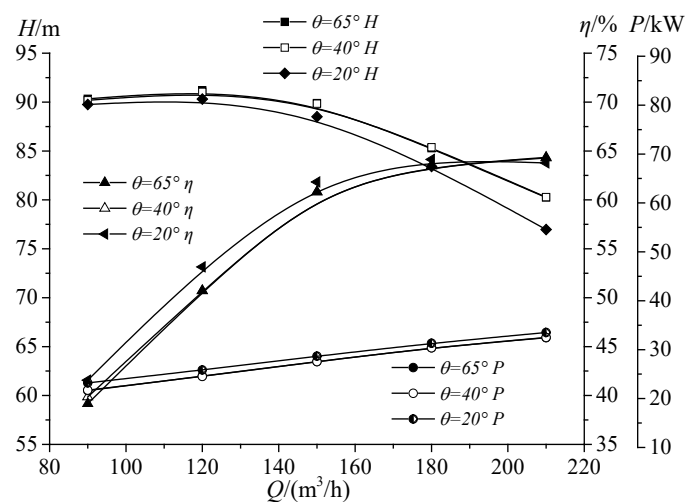

(a) First-stage impeller

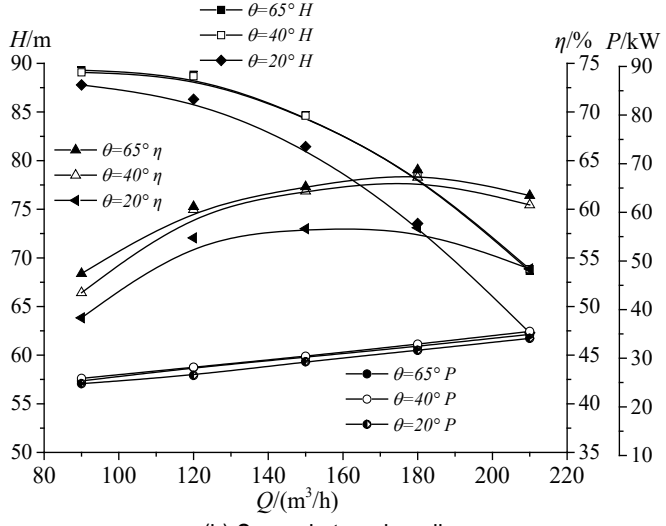

(b) Second-stage impeller

Figure 7 External characteristic curves of the first- and second-stage impellers of the series-parallel centrifugal pump under the three valve openness degrees

Pressure distributions on the intermediate rotary surface of the first- and second-stage impellers are shown in Fig. 9. The upper edge is the impeller outlet, whereas the lower edge is the impeller inlet. The resistance of the second-stage pipe increases gradually with the decrease of valve openness, thereby decreasing the flow rate of the second stage and increasing that of the first stage. However, the flow rate of the second stage is still higher than that of the first stage. Although the flow rate of the second stage decreases slightly, the inflow loss at the inlet increases because of the increased resistance in the suction chamber. As a result, the pressure at the impeller inlet increases considerably and easily causes cavitation. The low-pressure region at the impeller inlet increases slightly due to the increase in the flow rate of the first stage. Furthermore, the pressure distribution on the first-stage impeller changes slightly.

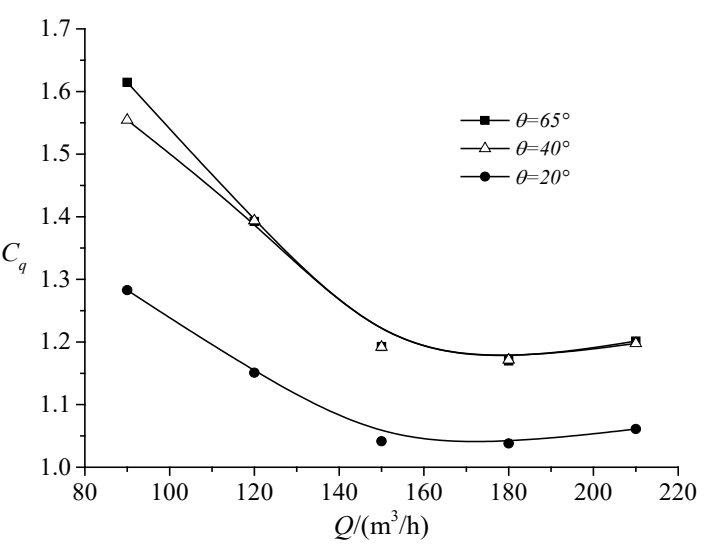

Figure 8 Changes in the first- and second-stage flow ratios with the overall flow rate of the series-parallel centrifugal pump

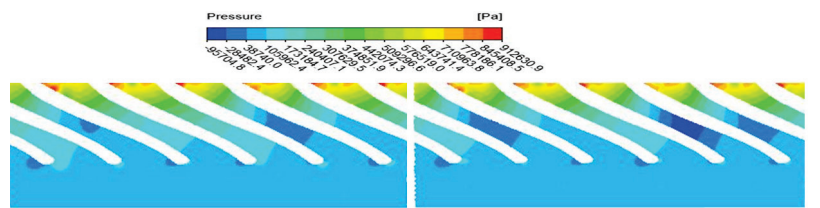

(a) First-stage impeller at $\theta=65^{\circ}$ (b) Second-stage impeller at $\theta=65^{\circ}$

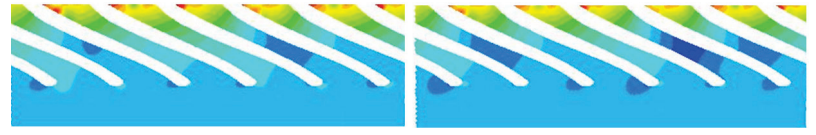

(c) First-stage impeller at $\theta=40^{\circ}$ (d) Second-stage impeller at $\theta=40^{\circ}$

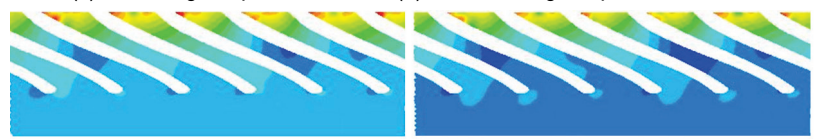

(e) First-stage impeller at $\theta=20^{\circ}$ (f) Second-stage impeller at $\theta=20^{\circ}$

Figure 9 Pressure distributions on the first- and second-stage impellers under different openness degrees of the inlet valve
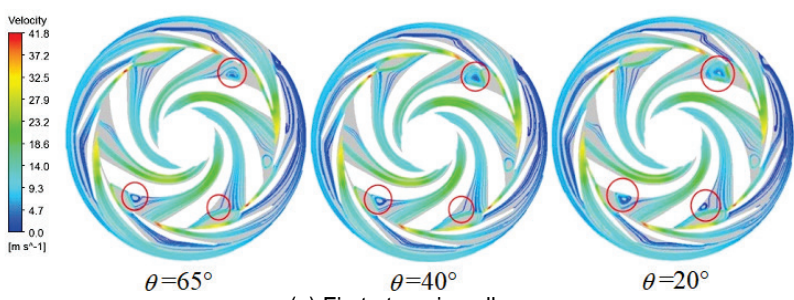

(a) First-stage impeller
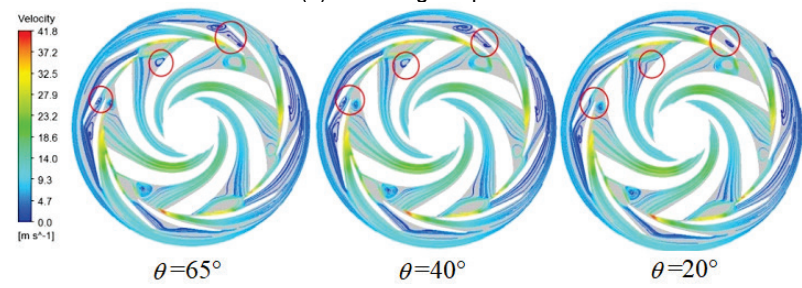

(b) Second-stage impeller

Figure 10 Section streamlines on the first- and second-stage impellers and guide vanes under different openness degrees of the inlet valve

Section streamlines on the first- and second-stage impellers and guide vanes are shown in Fig. 10. When the openness decreases, the first-stage impeller is influenced by flow rate increase, hence, the generation of separation eddies at the impeller and guide vane reduces to some extent However, the flow rate is still lower than that under the rated condition. Therefore, the reduction of openness causes flow instability in the second-stage channel. Moreover, the flow rate in the second-stage channel decreases, and the eddies in this channel intensify. 


\subsection{Influence of the Openness of Inlet One-way Valve on Pressure Fluctuation \\ 4.3.1 Arrangement of Monitoring Points}

Fluid pressure fluctuation in pump channels is a major cause of pump vibration. Unsteady simulation calculation of the rated condition under the three openness degrees is conducted to discuss the influence of the openness of the inlet one-way valve on the fluid pressure fluctuation in pump channels. Several pressure monitoring points are placed in the computational domain to monitor internal pressure changes in the channel. The arrangement of pressure monitoring points is shown in Fig. 11. One monitoring point is set at the middle position of the inlet of the diffusion section of each vane channel. Then, seven monitoring points are set uniformly and circumferentially at the middle position of the volute along the channel. Meanwhile, one monitoring point is set at the volute tip close to the volute. All monitoring points are placed on the middle section. The calculation initial condition based on the steady calculation results file is documented. The calculation period is six rotation periods of impeller, which accounts for $0.12414 \mathrm{~s}$. The time step length is 0.0002299 , and each rotation period has 90 time steps. The calculation results of the last rotation period are selected for analysis to ensure the accuracy of the results.

To eliminate interferences of static pressure on the result analysis, pressure coefficient $c_{p}=(p-\bar{p}) /\left(0.5 \rho u_{2}^{2}\right)$

is introduced for analyzing the results, where $p$ is the instantaneous pressure value of the monitoring point $(\mathrm{Pa})$, $\bar{p}$ is the mean pressure value of the monitoring points in the last rotation period $(\mathrm{Pa}), \rho$ is the fluid density $\left(\mathrm{kg} / \mathrm{m}^{3}\right)$, and $u_{2}$ is the circumferential speed at the impeller outlet $(\mathrm{m} / \mathrm{s})$

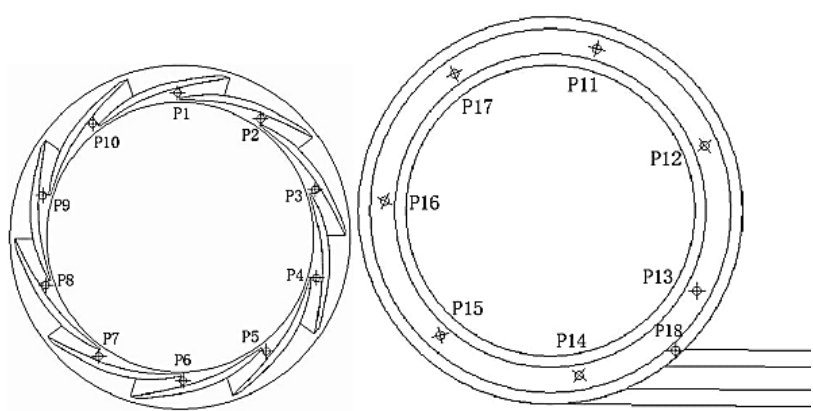

Figure 11 Distribution of pressure monitoring points

\subsubsection{Pressure fluctuation analysis}

The frequency domains of the monitoring points on the second-stage radial guide vane and volute are shown in Fig. 12 and Fig. 13. The rotation frequency is $f_{n}=N / 60=48.33$ $\mathrm{Hz}$, and the blade-passing frequency is $f=6 f_{n}=289.98 \mathrm{~Hz}$.

As shown in Fig. 12 and Fig. 13, the pressure fluctuation in the flow passage components of the seriesparallel centrifugal pump is mainly determined by rotation frequency, blade-passing frequency, and their higher harmonics. Influenced by the rotor-stator interaction of the impeller, pressure fluctuation in the radial guide vane is mainly composed of blade-passing frequency and its higher harmonics. This fluctuation mainly includes 1, 2, 3, and 4 blade-passing frequencies at 289.85, 579.71, 869.57, and $1159.42 \mathrm{~Hz}$, respectively. The maximum fluctuation amplitude occurs at the 1 blade-passing frequency. The amplitude at the 2 blade-passing frequencies is also at a high level. Amplitudes under other frequencies are small and decrease with the increase of frequency. Fluctuation curves under the three openness degrees present a consistent trend, thereby showing a small difference. At the wave peak of fluctuation, the amplitude under a small openness degree is slightly smaller than that under a large openness degree.

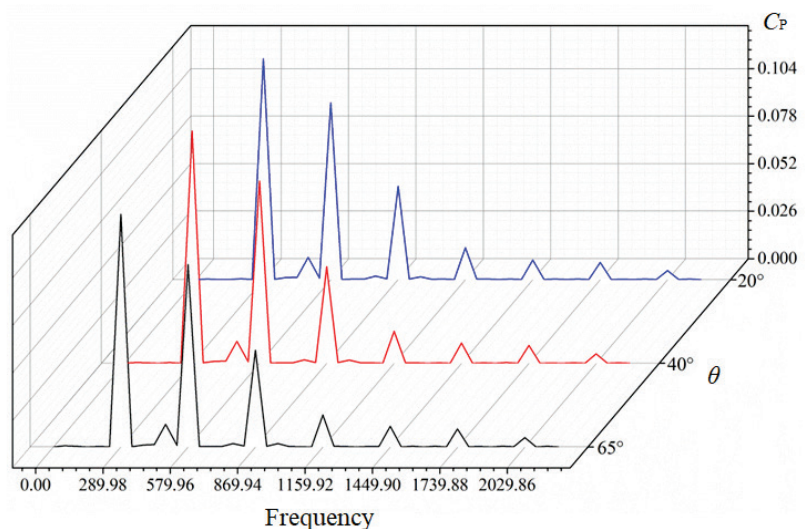

(a) Pressure frequency domain at P5

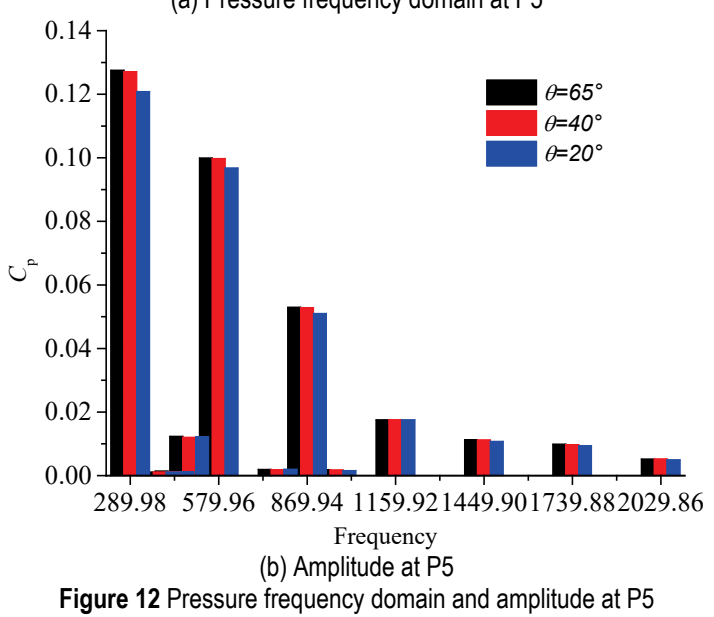

In the annular volute, pressure fluctuation is dominated by high harmonics of blade-passing frequency and that of rotation frequency simultaneously. It is mainly composed by 1,2 , and 5 blade-passing frequencies at $289.85,579.71$, and $1449.28 \mathrm{~Hz}$, respectively, and rotation frequencies at $483.30 \mathrm{~Hz}$. The maximum fluctuation amplitude occurs at the 2 blade-passing frequencies, which is slightly higher than that at the rotation frequencies. Although no evident law is observed under other frequencies, their amplitudes are relatively small. Pressure fluctuation in the volute decreases dramatically due to the radial guide vane. In comparison with the amplitude in guide vane, the fluctuation amplitude is nearly one order of magnitude smaller. Similar to situations in the guide vane, fluctuation trends under the three openness degrees are consistent. At the wave peak of the fluctuation, the amplitude under a small openness degree is slightly lower than that under a large openness degree. Therefore, valve changes can influence pressure fluctuation at the monitoring point to a certain extent. Influenced by the reduction of flow rate, the fluctuation amplitude decreases slightly at the wave peak. 


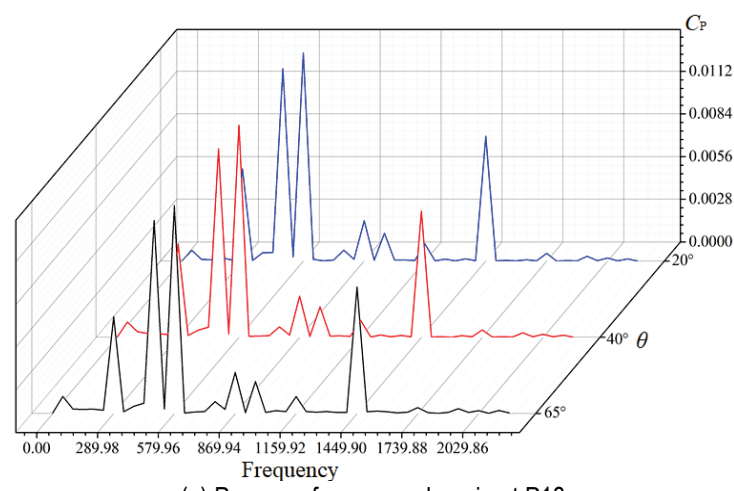

(a) Pressure frequency domain at P18

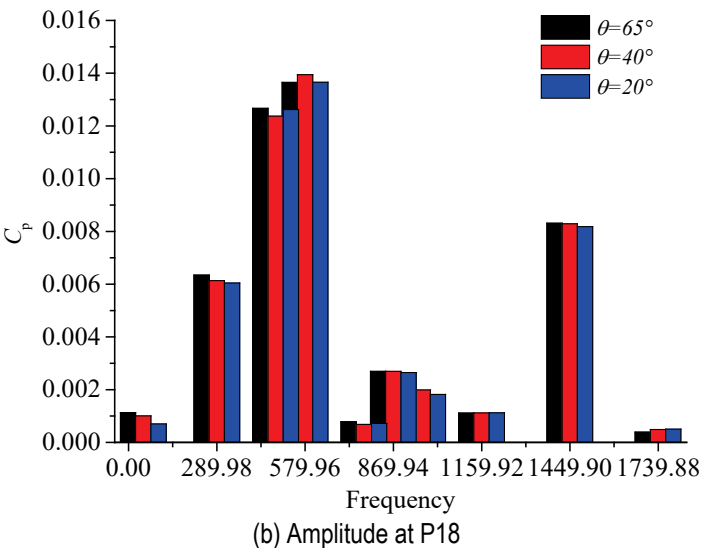

Figure 13 Pressure frequency domain and amplitude at P18.

The last period in unsteady calculation is selected to further explore the influence of valve openness on internal flow field. One section of the outlet diffusion of the annular volute, which is close to the volute tip, is analyzed. One horizontal section of the volute diffusion pipe where this eddy lies is analyzed. Turbulence kinetic energy on section at different moments when $\theta=65^{\circ}, 40^{\circ}$, and $20^{\circ}$ is shown in Fig. 14.

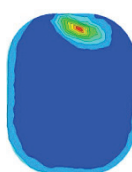

$t=0.1035 \mathrm{~s}$

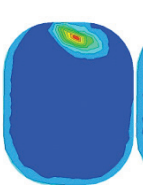

$t=0.1035 \mathrm{~s}$

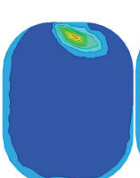

${ }_{t}=0.1035 \mathrm{~s}$

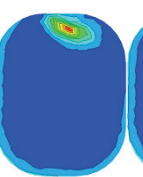

${ }_{t}=0.1076 \mathrm{~s}$

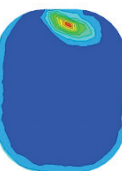

$t_{t}=0.1076 \mathrm{~s}$

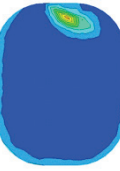

${ }_{t}=0.1076 \mathrm{~s}$

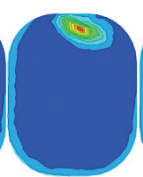

${ }_{t}=0.1117 \mathrm{~s}$

(a) $\theta=20^{\circ}$

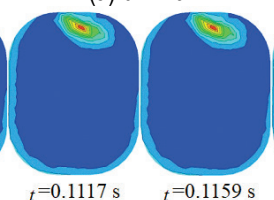

(b) $\theta=40^{\circ}$

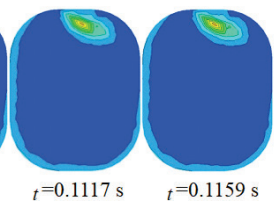

(c) $\theta=65^{\circ}$
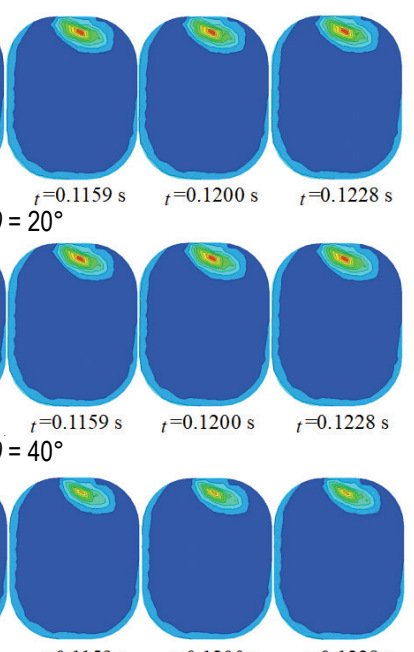

${ }_{t}=0.1200 \mathrm{~s} \quad{ }_{t}=0.1228 \mathrm{~s}$
Figure 14 Turbulence kinetic energy on the section of the volute diffusion pip

Under the same openness degree, the eddy changes slightly with time. Pressure fluctuation caused by the eddy should be analyzed by other methods. Under different openness degrees, the eddy strength decreases under small openness. The eddy scale when $\theta=20^{\circ}$ is smaller than that when $\theta=65^{\circ}$. Therefore, the turbulence strength at the central area is weakened. As the valve openness decreases, the second-stage flow rate decreases accordingly. The second-stage flow rate under full openness is higher than the design flow rate. Consequently, the flow reduction improves the flow state of the fluid, thereby decreasing the pressure fluctuation peak and slightly weakening the eddy strength at the outlet. The flow rate under a small openness is still higher than the design flow rate. Thus, the corresponding influence is similar, thereby resulting in the poor improvement in relation to the overall series-parallel centrifugal pump. The eddy is also discovered at the corresponding position to the first-stage impeller. However, changes in the second-stage impeller are opposite. With the reduced openness, the development of turbulence at the eddy center intensifies.

\section{CONCLUSION}

This study aims to disclose the influence of the openness of inlet one-way valve on the performances of a series-parallel centrifugal pump and the corresponding mechanism for inducing pressure fluctuation. As such, the internal flow in the pump under different openness degrees is predicted by combining numerical simulation and model experiment. Change law of pressure fluctuation under different openness degrees is also studied. The following conclusions can be drawn.

(1) When $\theta \geq 40^{\circ}$, the openness of the inlet one-way valve slightly influences the performance of the seriesparallel centrifugal pump. When $\theta<20^{\circ}$, the overall performance of the centrifugal pump declines with the reduction of openness. However, the first- and secondstage flow rates tend to be equal. Therefore, the openness of the inlet one-way valve shall be kept no lower than $40^{\circ}$ in engineering applications.

(2) With the reduction of openness of the inlet one-way valve, the pressure close to the inlet of the second-stage impeller declines. As a result, the second-stage impeller easily develops cavitation, and the eddy flow in the impeller intensifies. Nevertheless, the first-stage impeller is influenced slightly. With the changes in the openness, fluctuation frequency remains the same. However, the fluctuation amplitude under a small openness degree is lower than that under a large openness degree. Given a small openness degree, the eddy strength close to the volute tip of the second-stage volute weakens, and that close to the first-stage volute increases. This result is a response to the reduction of flow rate difference between the first and second stages,

(3) In engineering applications, the second-stage valve shall be at the maximum openness. Moreover, to maximize the performance of the series-parallel centrifugal pump, the first stage flow channel shall be optimized and the resistance shall be reduced to make the first- and secondstage flow rates equal.

In this study, the physical model under different openness degrees of inlet one-way valve is constructed by combining numerical simulation and model experiment. The internal flow law and the pressure fluctuation in the series-parallel centrifugal pump under different openness degrees are gained. The results can provide important references to vibration and noise reduction of transmission equipment in ship engineering. However, given the lack of visualized experimental data of the internal flow field 
under different conditions, further experimental studies can integrate the particle image velocimetry for a contrastive analysis of the geometric model; this integration is conducive to the systematic analysis on the root causes of pressure fluctuation.

\section{Acknowledgements}

This research was funded by the Natural Science Foundation of China under Grant No. 51806053.

\section{REFERENCES}

[1] Shukla, S. N., Khare, R., \& Prasad V. (2017). Numerical prediction of NPSHR characteristics of double suction centrifugal pump. International Journal of Engineering \& Technology, 9(2), 1280-1287. https://doi.org/10.21817/ijet/2017/v9i2/170902255

[2] Song, Y., Yu, Z., Shi, G., \& Liu, X. (2018). Influence of impeller staggered arrangement on radial force and pressure fluctuation for a double-suction centrifugal pump. Advances in Mechanical Engineering, 10(6), 1-13. https://doi.org/10.1177/1687814018781467

[3] Li, Q., Yan, H., \& Shi, H. X. (2016). Simulation of nonoverload characteristics of serial-parallel centrifugal pumps. International Journal of Simulation Modeling, 15(4), 688698. https://doi.org/10.2507//JSIMM15(4)9.364

[4] Jiang, X. P., Wang, C., Wu, J. H., Shi, W. D., Liu, S. H., \& Yang, Y. F. (2017). Effect of diffuser inlet width on cantilever multistage centrifugal pump. DYNA - Ingeniería e Industria, 92(1), 63-70.

[5] Lu, J., Yuan, S., Parameswaran, S., Yuan, J., Ren, X., \& Si, Q. (2017). Investigation on the vibration and flow instabilities induced by cavitation in a centrifugal pump. Advances in Mechanical Engineering, 9(4). https://doi.org/10.1177/1687814017696225

[6] Yang, J., Pavesi, G., Liu, X., Xie, T., \& Liu, J. (2018). Unsteady flow characteristics regarding hump instability in the first stage of a multistage pump-turbine in pump mode. Renewable Energy, 127, 377-385. https://doi.org/10.1016/j.renene.2018.04.069

[7] Rakibuzzaman, M., Kim, K., \& Suh, S. H. (2016). Numerical analysis of cavitation phenomena with variable speed centrifugal pump. Journal of Power Technologies, 96(4), 306-311.

[8] Li, X., Gao, P., Zhu, Z., \& Li, Y. (2018). Effect of the blade loading distribution on hydrodynamic performance of a centrifugal pump with cylindrical blades. Journal of Mechanical Science \& Technology, 32(3), 1161-1170. https://doi.org/10.1007/s12206-018-0219-4

[9] Lei, H. X., Zhao, J. L., \& Wang, Z. J. (2016). Numerical Simulation and Experiments on Muzzle Blast Overpressure in Large-Caliber Weapons. Journal of Engineering Science and Technology Review, 9(5), 111-116. https://doi.org/10.25103/jestr.095.17

[10] Chai, L. P., Ye, H., Ren, Z. M., \& Li, H. (2016). Influence of impeller parameters on pressure fluctuation in pump outlet. Journal of drainage and irrigation machinery engineering, 34(8), 645-650.

[11] Li, X., Zhu, Z., Li, Y., \& Chen, X. (2016). Experimental and numerical investigations of head-flow curve instability of a single-stage centrifugal pump with volute casing. Proceedings of the Institution of Mechanical Engineers Part A Journal of Power \& Energy, 230(7), 633-647. https://doi.org/10.1177/0957650916663326

[12] Rosen H. (2010).Variability of pump system performance, The Journal of the Southern African Institute of Mining and Metallurgy, 110, 79-87.
[13] Liu, Y., Tan, L., Liu, M., \& Xu, Y. (2017). Influence of Prewhirl Angle and Axial Distance on Energy Performance and Pressure Fluctuation for a Centrifugal Pump with Inlet Guide Vanes. Energies, 10(695), 1-14.

[14] Sukamoto H., Ian D. M., \& Shi F. (2001). Numerical study of pressure fluctuations caused by impeller-diffuser interaction in a diffuser pump stage. ASME Journal of Fluids Engineering, 123(3), 466-474. https://doi.org/10.1115/1.1385835

[15] Furukawa, A., Takahara, H., Nakagawa, T., \& Ono, Y. (2007). Pressure fluctuation in a vaned diffuser downstream from a centrifugal pump impeller. International Journal of Rotating Machinery, 9(4), 285-292. https://doi.org/10.1155/S1023621X03000265

[16] Wang, H. (2003). Experimental and numerical study of unsteady flow in a diffuser pump at off-design conditions. Journal of Fluids Engineering, 125(5), 767-778. https://doi.org/10.1115/1.1603305

[17] Guo, S. \& Maruta, Y. (2005). Experimental investigations on pressure fluctuations and vibration of the impeller in a centrifugal pump with vaned diffusers. JSME International Journal, 48(1), 136-143. https://doi.org/10.1299/jsmeb.48.136

[18] Khalifa, A. E., Al Qutub, A. M., \& Ben-Mansour, R. (2011). Study of pressure fluctuations and induced vibration at blade-passing frequencies of a double volute pump. Arabian Journal for Science \& Engineering, 36(7), 1333-1345. https://doi.org/10.1007/s13369-011-0119-8

[19] Ruan, X., Ma, Q., Lv, X., Liu, D., \& Zhang, B. (2017). Design and Experimental Study on the Automatic Speed Control System of a Pneumatic Submersible Pump. Journal of Engineering Science \& Technology Review, 10(4), 25-30. https://doi.org/10.25103/jestr.104.04

[20] Liu, M. Q., Li, Q. W., Bai, Y. H., Liu, Z. Y., \& He, P. J. (2012). Efficiency and pressure pulsation analysis of a double suction centrifugal pump with different arrangement impellers. Advanced Materials Research, 433, 709-715. https://doi.org/10.4028/www.scientific.net/AMR.433-440.709

[21] Si, Q., Yuan, J., Yuan, S., Wang, W., Zhu, L., \& Bois, G. (2014). Research article numerical investigation of pressure fluctuation in centrifugal pump volute based on SAS model and experimental validation. Advances in Mechanical Engineering, 2014(1), 323-328.

[22] Langthjem, M. A. \& Olhoff, N. (2004). A numerical study of flow-induced noise in a two-dimensional centrifugal pump. Part I. Hydrodynamics, Journal of Fluids \& Structures, 19(3), 349-368. https://doi.org/10.1016/j.jluidstructs.2004.01.003

[23] Yang, A., Lang, D., Li, G., Chen, E., \& Dai, R. (2014). Numerical research about influence of blade outlet angle on flow-induced noise and vibration for centrifugal pump. Advances in Mechanical Engineering, 2, 1687-8132. https://doi.org/10.1155/2014/583482

[24] Su, X. Z., Yang, C. X., Li, Y. B., \& Li, Q. (2014). Effect of impeller inlet condition on non-overload performance of serial-parallel centrifugal pump. Transaction of the Chinese society of agricultural engineering, 30(13), 60-67.

[25] Zhao, X., Xiao, Y., Wang, Z., Luo, Y., Cao, L., \& Zhao, X. (2018). Unsteady flow and pressure pulsation characteristics analysis of rotating stall in centrifugal pumps under off design conditions. Journal of Fluids Engineering, 140(2), 16. https://doi.org/10.1115/1.4037973

[26] Li, X., Jiang, Z., Zhu, Z., Si, Q., \& Li, Y. (2018). Entropy generation analysis for the cavitating head-drop characteristic of a centrifugal pump. Proceedings of the Institution of Mechanical Engineers Part C, Journal of Mechanical Engineering Science, 1-10. https://doi.org/10.1177/0954406217753458

[27] Feng, H. D., Xu, L., \& Xu, R. P. (2014). Uncertainty analysis using the thermodynamic method of pump efficiency testing. Proceedings of the Institution of Mechanical Engineers, Part 
C: Journal of Mechanical Engineering Science, 218(5), 543-

555. https://doi.org/10.1243/095440604323052328

\section{Contact information:}

\section{Hao YAN, PhD}

(Corresponding author)

School of Mechanical Engineering, Hefei University of Technology,

193 Tunxi Road, Hefei, 230009, Anhui, China

E-mail: yanying0708@126.com

Qiang LI, Professor

School of Mechanical Engineering, Hefei University of Technology,

193 Tunxi Road, Haidian district, Beijing, China

E-mail: hfliqiang@163.com

\section{Liang CHEN, Senior Engineer}

The Chamber of Science and Technology of Anhui Province,

46 Mingguang Road, Hefei, Anhui, China

E-mail: hfchenliang@foxmail.com

\section{Yu ZHANG}

School of Mechanical Engineering, Hefei University of Technology,

46 Mingguang Road, Hefei, Anhui, China

E-mail: 497758698@qq.com

\section{Jaini RAGHU}

Research and Production Centre "EIP", India

M. G. Road IFFCO Chowk, Gurugram, Haryana,122002, India

E-mail: raghujaini@empireindia.com 